\title{
La espironolactona reduce la morbimortalidad en los pacientes con insuficiencia cardíaca severa
}

Pitt B, Zannad F, Remme WJ, et al. The effect of spironolactone on morbidity and mortality in patients with severe heart failure. N Engl J Med 1999:341:709-17.

\section{Objetivo}

Evaluar si la adición de espironolactona al tratamiento estándar reduce significativamente la mortalidad en pacientes con insuficiencia cardíaca (IC) severa.

\section{Diseño}

Ensayo clínico multicéntrico aleatorizado, doble ciego, controlado con placebo.

\section{Lugar}

Participaron 195 centros de 15 países.

\section{Pacientes}

Se incluyeron 1663 pacientes con IC clase funcional III o IV y fracción de eyección (FE) $\leq$ a $35 \%$ que estuvieran tratados con inhibidores de la enzima convertidora de angiotensina (IECA), un diurético de asa y, optativamente, digoxina.

\section{Intervención}

Se asignaron 841 sujetos al grupo placebo (GP) y 822 a $25 \mathrm{mg} /$ día de espironolactona (GE). Los criterios de exclusión fueron: potasemia mayor de $5 \mathrm{mEq} / \mathrm{L}$, creatininemia mayor a $2,5 \mathrm{mg} \%$, valvulopatía quirúrgica, cardiopatía congénita, angina inestable o serias comorbilidades

\section{Medición de los resultados}

Resultado principal: mortalidad por cualquier causa. Los resultados secundarios incluyeron la mortalidad cardíaca y/o internación por causas cardíacas y el cambio de la clase funcional.

\section{Resultados}

El estudio fue tempranamente suspendido ya que un análisis preliminar* demostró la eficacia de la espironolactona (Ver tabla). El seguimiento

Fuente de financiamiento:Laboratorios Searle, EE.UU. medio fue de 24 meses. La reducción del riesgo de muerte fue independiente de la FE, de la causa de la IC, de la creatininemia, de la edad, del uso de IECA o digitálicos (subgrupos preestablecidos); como así también de la clase funcional, del empleo de suplementos de potasio, beta bloqueantes o de la región geográfica involucrada en el estudio.

Se establecieron tres categorías para evaluar los cambios de la clase funcional. En el GP el 33\% tuvo mejoría, el 18\% ausencia de cambios y el $48 \%$ presentaron empeoramiento o muerte. En el GE, en cambio, los valores fueron 41,21 y $38 \%$ respectivamente, siendo las diferencias entre los grupos estadísticamente significativas. El 23,8\% del GP y el 26\% del GE abandonaron el tratamiento por falta de respuesta, efectos adversos ( 5 y $8 \%$, respectivamente) o razones administrativas. No se hallaron diferencias entre los grupos en la natremia, la presión arterial o la frecuencia cardíaca. La hiperkalemia severa ocurrió en el 1\% en el GPy en el $2 \%$ en el GE (diferencias no significativas). La incidencia de ginecomastia fue mayor en el GE respecto al GP (10\% vs $1 \%, \mathrm{p}<0,001)$.

\begin{tabular}{|c|c|c|c|c|c|c|}
\hline Variable & $\begin{array}{l}\text { Placebo } \\
(\mathrm{n}=841)\end{array}$ & $\begin{array}{l}\text { Espirono } \\
\text { lactona } \\
\text { ( } n=822)\end{array}$ & $\begin{array}{l}\text { Riesgo } \\
\text { relativo* } \\
\text { (IC95\%) }\end{array}$ & $\begin{array}{l}\text { RRA* } \\
(\%)\end{array}$ & NNT* & $p$ \\
\hline $\begin{array}{l}\text { Total } \\
\text { de muertes }\end{array}$ & 386 & 284 & $\begin{array}{c}0,70 \\
(0,60-0,82)\end{array}$ & 11 & 9 & 0,001 \\
\hline $\begin{array}{l}\text { Muertes } \\
\text { cardíacas }\end{array}$ & 314 & 226 & $\begin{array}{c}0,69 \\
(0,58-0,82)\end{array}$ & 10 & 10 & 0,001 \\
\hline $\begin{array}{l}\text { Por progresió } \\
\text { de la IC }\end{array}$ & ón 189 & 127 & $\begin{array}{c}0,64 \\
(0,51-0,80)\end{array}$ & 7 & 14 & 0,001 \\
\hline $\begin{array}{l}\text { Por muerte } \\
\text { súbita }\end{array}$ & 110 & 82 & $\begin{array}{c}0,71 \\
(0,54-0,95)\end{array}$ & 3 & 32 & 0,02 \\
\hline $\begin{array}{l}\text { Por infarto } \\
\text { de miocardio }\end{array}$ & 15 & 17 & $\begin{array}{c}1,16 \\
(0,58-2,30)\end{array}$ & - & - & 0,67 \\
\hline $\begin{array}{l}\text { Internacione } \\
\text { por insuficien } \\
\text { cardíaca }\end{array}$ & $\begin{array}{l}\text { ncia } \\
663\end{array}$ & 413 & $\begin{array}{c}0,65 \\
(0,54-0,77)\end{array}$ & 29 & 3 & 0,001 \\
\hline
\end{tabular}

*Ver Glosario (RRA y NNT calculados por el autor)

Conclusiones

La adición de espironolactona al tratamiento estándar reduce significativamente la morbimortalidad en los pacientes con IC severa.

\section{COMENTARIO}

El Estudio Randomizado de Evaluación de Aldactone (sigla inglesa RALES) debió suspenderse dada la notoria reducción en la morbimortalidad experimentada en el GE, lo que hacía antiético privar al GP de los beneficios de la espironolactona (si se lo compara con el tratamiento estándar, agregando espironolactona a sólo nueve pacientes durante dos años se salva una vida).

La trascendencia del estudio fue tal, que el "New England" lo puso completo en su página Web, junto a una editorial, dos meses antes de la fecha de publicación. La disminución del riesgo de mortalidad o internación se evidenció luego de dos meses de tratamiento y los beneficios fueron aumentando durante todo el seguimiento, incluyéndose la mejoría en la clase funcional.

Estos resultados concuerdan con los reconocidos efectos de la aldosterona. Inicialmente se consideraba que ésta sólo incidía en la IC reteniendo sodio o eliminando potasio. La baja dosis de bloqueo con espironolactona empleada en el estudio (25mg/día), con la que no se modifica ni el peso ni la natriuresis, ${ }^{1}$ sugiere otros mecanismos aldosterónicos más poderosos como los que se ejercen sobre la fibrosis miocárdica y vascular, ${ }^{2-3}$ sobre la disfunción de los barorreceptores y sobre la prevención de la captación miocárdica de norepinefrina. ${ }^{4}$

Si bien no puede establecerse con precisión, los autores sugieren que al blo*Ver Glosario

quearla, se reduciría la progresión de la IC y la mortalidad (por limitación de la retención de sodio y la fibrosis), como así tambien la muerte súbita (por actuación sobre el potasio y la norepinefrina $)^{1}$. Asimismo, la importancia de la aldosterona fue subestimada por años suponiéndose que los IECA eliminaban su producción ${ }^{5}$, pero aún a dosis óptimas (no siempre alcanzadas) el bloqueo es incompleto y transitorio, pues también depende del potasio 6 y su metabolización hepática disminuye en la IC.

Este estudio representa un importante avance terapéutico y coloca a la espironolactona dentro del tratamiento estándar de pacientes con IC por disfunción sistólica en clase funcional III-IV (resta saber su costo-efectividad en pacientes menos severos y su efecto cuando se usa asociada a betabloqueates).

Existiendo una adecuada función renal y monitoreando el potasio, la suspensión por hiperkalemia es rara. Si bien la incidencia de ginecomastia fue mayor (existen fármacos menos antiandrogénicos en desarrollo ${ }^{7}$ su tolerancia es buena. Para concluir, podemos decir que la combinación de espironolactona con IECA y diuréticos de asa permite reducir las dosis de los últimos y disminuir la suplementación de potasio, pero por sobre todo, reduce significativamente la morbimortalidad en los pacientes con IC.

\section{Dr. Agustín Ciapponi}

Unidad de Medicina Familiar y Preventiva. Hospital Italiano de Buenos Aires.

Referencias

1. The RALES Investigators. Effectiveness of spironolactone added to an angiotensin-converting enzyme inhibitor and a loop diuretic for severe chronic congestive heart failure (the Randomized Aldactone Evaluation Study [RALES]). Am J Cardiol 1996:78:902-7.

2. Weber KT, Brilla CG. Pathological hypertrophy and cardiac interstitium: fibrosis and renin-angiotensin-aldosterone system. Circulation 1991;83:1849-65.

3. Brilla CG, Pick R, Tan LB, Janicki JS, Weber KT. Remodeling of the rat right and left ventricles in experimental hypertension. Circ Res 1990;67:1355-64.

4. Barr CS, Lang CC, Hanson J, Arnott M, Kennedy N, Struthers AD. Effects of adding spironolactone to an angiotensin-converting enzyme inhibitor in chronic congestive heart failure secondary to coronary artery disease. Am J Cardiol 1995;76:1259-65.

5. Weber KT. Aldosterone and Spironolactone in Heart Failure. N EngL J Med 1999;341.

6. Struthers AD. Aldosterone escape during angiotensin-converting enzyme inhibitor therapy in chronic heart failure. J Card Fail 1996;2:47-54.

7. de Gasparo M, Joss U, Ramjoue HP, et al. Three new epoxy-spirolactone derivatives: characterization in vivo and in vitro. J Pharmacol Exp Ther 1987;240:650-6. 